\title{
A Review of Psychiatric Disorders Associated with Celiac Disease
}

\author{
Mitchell B. Liester* and Maya G. Liester \\ University of Colorado School of Medicine, P.O. Box 302 Monument, CO 80132 USA
}

*Corresponding author: Mitchell B. Liester, Associate Professor of Psychiatry, University of Colorado School of Medicine, USA, Tel: +719-488-0024; Fax: +719-488-6672; E-mail: mitchell.liester@ucdenver.edu

Received date: July 14, 2017; Accepted date: August 05, 2017; Published date: August 12, 2017

Citation: Liester MB, Liester MG (2018) A Review of Psychiatric Disorders Associated with Celiac Disease. Dual Diagn Open Acc Vol.2 No.2: 1.

Copyright: (C2018 Liester MB, et al. This is an open-access article distributed under the terms of the Creative Commons Attribution License, which permits unrestricted use, distribution, and reproduction in any medium, provided the original author and source are credited.

\section{Abstract \\ Celiac Disease (CD) is an autoimmune enteropathy triggered by the ingestion of gluten in genetically susceptible individuals. Although classic symptoms of $C D$ primarily involve the gastrointestinal tract, extra-intestinal symptoms are common as well. In this review, we examine psychiatric disorders that occur in association with $C D$, examine pathophysiological mechanisms that may be responsible for these comorbid conditions, and suggest areas of research that could both improve our understanding and reveal potential new treatments for these psychiatric disorders.}

Keywords: Gluten; Depression; Schizophrenia; Anxiety; Autism spectrum disorders; Eating disorders; ADHD

\section{Introduction}

Celiac Disease (CD) is an autoimmune enteropathy caused by an inappropriate immune response to gluten in genetically susceptible individuals [1]. Individuals with untreated CD are at increased risk for both gastrointestinal (GI) and extraintestinal problems. A subset of individuals with $C D$ is at increased risk for psychiatric disorders [2]. The basis for this increased prevalence of psychiatric disorders in $C D$ and the common pathophysiological mechanisms responsible for these comorbid disorders remain to be elucidated.

\section{What is gluten?}

The term gluten refers to a group of proteins found in wheat, barley, and rye consisting of gliadin and glutenin subcomponents [3]. When added to bread, gluten supports bread rising, provides elasticity, and helps bread keep its shape [4-6].

Gluten proteins are difficult to digest in the human GI tract due to their high proline content [7]. These undigested gluten proteins are toxic for individuals with CD [8].

\section{What is Celiac Disease?}

Celiac Disease is defined as a chronic, immunologically determined enteropathy precipitated by the ingestion of glutencontaining foods in genetically predisposed individuals [9].

Samuel Gee first described CD more than a century ago [10]. But, it wasn't until the 1940's that the Dutch pediatrician, Willem-Karel Dicke, identified wheat flour as the causative agent [11]. Many factors influence the onset and progression of CD including genetic predisposition and environmental influences.

Individuals with CD may exhibit a polymorphous clinical presentation. In children, characteristic features include malabsorption syndrome with growth failure, malnutrition, chronic diarrhea, steatorrhea, edema, abdominal distention, and muscle wasting [12]. Adults with CD manifest a wider range of symptoms than children [13].

\section{Epidemiology of CD}

The prevalence of $C D$ varies widely throughout the world. In Europe and North America, about $1 \%$ of the population is affected [14]. Germany has one of the lowest prevalence rates $(0.3 \%)$ [15] and the Saharawi population from Western Sahara has one of the highest (5.6\%) [14].

The prevalence of $C D$ has been found to be increasing with time [16]. The presence of serological markers for $C D$ has quadrupled in the United States during the last 50 years [17] and doubled in Finland in the last 20 years [18]. This increase was observed in blood samples that were collected and frozen decades apart. Thus, the increase in CD cannot be attributed solely to improved detection or changes in diagnostic criteria. Also, serological markers for CD have been found to increase within the same group of individuals over time, indicating that an abnormal response to gluten can develop over the course of one's lifetime [19]. Possible explanations for the increasing prevalence of $C D$ include higher gluten content in many current wheat varieties and increased consumption of wheat [20].

The majority of individuals with $C D$ remain undiagnosed. This fact has been illustrated by the concept of a "celiac iceberg" in which the overall prevalence of $C D$ equates to the total size of the iceberg, diagnosed cases represent the tip of the iceberg visible above the water line, and the submerged portion of the 
iceberg represents individuals with undiagnosed CD [21]. There are an estimated 5-10 undiagnosed cases for every diagnosed case of CD [13].

\section{Pathophysiology of CD}

$C D$ is a multifactorial disease with both genetic and environmental factors contributing to the development of this disorder.

Genetic factors: The high incidence of $C D$ in 1st-degree relatives of celiac patients (10-15\%) and high concordance rate in monozygotic twins (80\%) suggest a strong genetic component. The main determinants of genetic susceptibility to CD are the major histocompatability class II HLA molecules. More than $90 \%$ of individuals with CD carry one or two copies of the HLA-DQ2.5 gene. DQ2-negative CD patients are almost invariably HLA-DQ8 positive $[22,23]$.

The DQ2 and DQ8 haplotypes are necessary, but not sufficient, for the development of CD. These haplotypes are expressed in $98 \%$ of people with CD, $90 \%$ of people who are unaffected but have a relative with $C D$, and $55 \%$ of the general population [24]. However, only about $1 \%$ of the population will develop CD. Thus far, at least 39 non-HLA genes that confer a predisposition to $C D$ have been identified, most of which are involved in inflammatory and immune responses [25].

Environmental factors: The environmental risk factor with the highest correlation for developing $C D$ is exposure to gluten. Other risk factors include region of birth $[26,27]$ and season of birth $[28,29]$. Children born in the winter have a lower risk of developing $C D$ than children born in the spring or summer $[26,28,29]$.

Changes in gut microbiota and infection with certain viruses also increase the risk of developing CD [30-33]. Being born by elective caesarean section rather than vaginal delivery is another risk factor for CD [24].

The impact of breastfeeding and timing of gluten introduction on the subsequent development of $C D$ remain controversial, with some studies indicating a positive association [34,35] and others reporting no association [24,36-38].

\section{Pathogenesis of CD}

The development of $C D$ begins when dietary gliadin binds to CXCR3 receptors in the intestinal epithelium in genetically susceptible individuals [39]. This triggers the release of zonulin [40], a protein involved in the regulation of intercellular tight junctions [41]. Tight junctions represent the major barrier in the paracellular pathway $[40,42,43]$. Increased levels of zonulin cause loosening of tight junctions, resulting in disruption of the mucosal barrier and increased intestinal permeability [9].

Certain gluten peptides are highly resistant to proteolysis by gastric, pancreatic, and intestinal digestive proteases due to a large number of proline and glutamine residues [44]. Increased intestinal permeability resulting from increased zonulin allows these intact gluten peptides to cross the intestinal mucosa. After reaching the submucosa, proline and glutamine-rich gluten peptides are deamidated by the enzyme tissue transglutaminase type 2 (tTG2), which has specificity toward proline-rich peptides. The left-handed helical conformation of proline-rich gliadin peptides renders them better substrates for tTG2 [45]. The resultant immunostimulatory epitopes have a high affinity for HLA-DQ2 and DQ8 molecules expressed on the surface of T lymphocytes. These deamidated gliadin epitopes bind to HLADQ2 and DQ8 molecules, triggering inflammatory and immunemediated responses. The end result is damage to the mucosa of the duodenal tract, which is seen on biopsies as villous atrophy and crypt hyperplasia [12].

\section{How is CD diagnosed?}

Often, many years pass between the development of symptoms and the correct diagnosis of $\mathrm{CD}$. The median duration of time from first symptoms to diagnosis ranges from 4.9 to 9.7 years $[46,47]$. This delay in diagnosis is associated with impairment in quality of life [47]. It is important for clinicians to have a good understanding of both the classic and extraintestinal manifestations of this disorder in order to consider $C D$ in the differential diagnosis.

Definitive diagnosis of $C D$ is based on a thorough assessment of the presenting symptoms, a high index of suspicion, serological testing, and histological analysis of duodenal biopsies. Recently, it has been suggested that high tTG2antibody levels in a symptomatic patient have such high diagnostic accuracy that it may be possible to omit the duodenal biopsy [12].

\section{Treatment of CD}

Treatment of $C D$ involves a gluten free diet (GFD) for life. $A$ GFD involves a diet free from wheat, barley, rye and foods that have been cross-contaminated with gluten-containing foods. To be labeled "gluten-free," foods must contain $<20 \mathrm{mg} / \mathrm{kg}$ of gluten. Maintenance on a GFD for as long as 2 years may be required for individuals with $C D$ to make a full recovery [48].

A GFD reduces gut permeability [49] and zonulin levels [50]. This protects individuals with $C D$ against the risk of developing other diseases associated with $C D$ and normalizes their mortality. However, if untreated or neglected, CD is associated with numerous complications [13,51].

Novel therapies are being investigated as treatments for CD. Infliximab, a monoclonal antibody against tumor necrosis factor that is used in the treatment of autoimmune diseases, has shown promise in cases of refractory CD [52-54]. Other studies have investigated the synthetic zonulin-blocking peptide larazotide acetate as a potential treatment for CD [55-59]. In a single case study, a change in the gut microbiota resulted in full recovery from $C D[60]$.

\section{Extra-intestinal problems associated with $C D$}

In addition to intestinal damage, $C D$ is associated with a wide variety of extra-intestinal problems. These include: malignancies, dermatologic problems, neurologic disorders, dental enamel hypoplasia, rheumatologic conditions, chronic 
hepatitis, cardiac disease, osteoporosis, endocrine disorders, autoimmune disorders, and psychiatric disorders [13,51,61-65].

This article examines the connection between $C D$ and psychiatric disorders.

\section{Methods}

We conducted a PubMed literature search (1955-2016) looking for English language articles containing the search terms Celiac Disease (CD) and the following terms: depression (181 articles), bipolar disorder (11 articles), anxiety (80 articles), schizophrenia (96 articles), Autism Spectrum Disorder (ASD) (19 articles), Attention-Deficit/Hyperactivity Disorder (ADHD) (15 articles), and eating disorders (78 articles). All retrieved articles were screened and a subset of relevant abstracts was then selected for more detailed evaluation. The biographies of these articles were then searched for additional references. The final studies selected for inclusion in this review consisted of those articles that directly evaluated the association between Celiac Disease and the aforementioned psychiatric disorders.

\section{Results}

Comorbidity between psychiatric disorders and $C D$ has been observed for more than 60 years $[66,67]$. Several psychiatric disorders are associated with $C D$, the most common being: depression, Bipolar Disorder, anxiety disorders, schizophrenia, Autism Spectrum Disorders (ASD), eating disorders and Attention-Deficit/Hyperactivity Disorder (ADHD).

\section{Depression}

An association between depression and CD was described more than half a century ago [68]. Subsequently, numerous studies have found depression to be more common in individuals with CD than in controls [69-76]. The prevalence of depressive symptoms in individuals with $C D$ ranges from 6 to $69 \%$ [77]. A meta-analysis of 18 studies examining depression in adults with CD found depression is more common and/or more severe in adults with $C D$ than in healthy controls (overall metaanalysis effect size: 0.97 ) [78]. An increased risk of suicide has also been reported in individuals with $C D$ compared with controls [79].

Not all studies agree with the finding of an increased prevalence of depression in individuals with CD [80-84]. Some authors have suggested that depression occurring in $C D$ patients is the result of having a chronic disease rather than being directly related to having $C D$ [70] or is related to comorbid conditions, such as type 1 diabetes mellitus [80].

\section{Bipolar disorder}

Studies exploring a possible relationship between $C D$ and Bipolar Disorder (BD) have produced mixed results. Negative findings include a population-based cohort study in Sweden that found individuals with $C D$ were not at increased risk of developing BD [75] and a Danish study that found no familial relationship between autoimmune diseases and BD among 3.57 million individuals [85]. However, other studies describe an increased prevalence of BD among individuals with CD [86-89].

Elevated levels of antibodies associated with $C D$ have been found in individuals with BD. Increased levels of IgG antibodies to gliadin were found in 102 individuals with BD, which was highly significant when compared with 173 controls without psychiatric disorders $(p<0.0001)[90]$.

In a subsequent study, individuals hospitalized for acute mania had significantly increased levels of IgG antibodies to gliadin, but no other markers of CD. At six-month follow-up, levels of IgG anti-gliadin antibodies were not significantly different from those of controls. However, among individuals with mania, those with elevated IgG anti-gliadin antibody levels at six-month follow-up were significantly more likely to be rehospitalized [91].

In another study, levels of multiple autoantibodies were elevated in individuals with BD. The BD group had higher levels of one or more autoantibodies compared with controls $168.8 \%$ versus $39.6 \% ; p=0.043$ ). Furthermore, individuals with $B D$ were found to have twice as many autoantibodies per patient as controls. However, the difference was not statistically significant (1.5 versus $0.56 ; \mathrm{p}=\mathrm{ns}$ ). Anti-gliadin $\operatorname{lgG}$ antibodies were significantly more prevalent in individuals with $\mathrm{BD}$ versus controls (50\% versus $9.8 \%$ ) [92].

These studies suggest IgG anti-gliadin antibodies might be a biomarker as well as a prognostic indicator in a subset of individuals with $\mathrm{BD}$

\section{Anxiety disorders}

Several studies have found an increased risk of anxiety disorders in individuals with $C D$. These include a report that found state anxiety to be present in a higher percentage of individuals with $C D$ than controls, whereas no difference was found in trait anxiety. The authors interpreted this finding to indicate that anxiety is a reaction to the disabling symptoms of $C D$ rather than a personality trait of the individuals who suffer with CD [69].

In a subsequent study, state anxiety was again found to be increased in individuals with CD compared to controls $(71.4 \%$ versus $23.7 \%$; $p 0.0001)$, but no difference was seen in trait anxiety ( $25.7 \%$ versus $15.2 \%$; p:ns). After 1 year on a GFD, state anxiety symptoms improved significantly [93].

Individuals with $C D$ were evaluated for Social Phobia using the Liebowitz Social Anxiety Scale (LSAS) in another study. The percentage of individuals with CD who were found to have Social Phobia was significantly higher than in controls $170 \%$ versus $16 \% ; p<0.0001)$. There was no difference in the number of subjects with Social Phobia who were newly diagnosed versus those who were on a GFD (73.3\% versus $68 \% ; p=n s)$ [94].

A study using the Hospital Anxiety and Depression Scale to assess the prevalence of anxiety disorders among individuals with $C D$ found an increased prevalence of anxiety disorders in individuals with $\mathrm{CD}$ compared with controls (16.85 versus $5.7 \%$; $\mathrm{p}<0.001)$ [82]. 
Two studies evaluating Panic Disorder (PD) in individuals with $\mathrm{CD}$ found an increased risk of PD compared with controls (i.e. $13.9 \%$ versus $2.1 \%$; $p<0.001$ and $18.3 \%$ versus $5.4 \% ; p<0.001$ ) $[71,86]$.

Obsessive-compulsive behavior disorders have also been linked with CD. Individuals with CD who had been off gluten for a minimum of 1 year were evaluated using the Structured Clinical Interview for DSM (SCID) based on DSM-IV criteria to evaluate for axis I and II disorders. Twenty-eight out of 100 individuals with $C D$ showed obsessive-compulsive behavior disorders whereas only 10 healthy controls were found to have anxiety disorders. Additionally, individuals with $C D$ had significantly higher levels of both state and trait anxiety compared with controls ( $p=0.0001$ and $p<0.0001$ respectively) [70].

Not all studies demonstrate a positive association between CD and anxiety, however. A meta-analysis involving eleven studies examined whether $C D$ and anxiety are linked. Adults with $C D$ were not found to differ reliably from healthy controls in terms of anxiety [78]. Other studies similarly found no statistical difference in anxiety between individuals with $C D$ who were on a GFD and healthy controls $[83,84]$.

\section{Schizophrenia}

The association between $C D$ and schizophrenia may be the strongest of any psychiatric disorder [95]. In fact, psychosis can be the presenting symptom of CD [96].

More than 60 years ago, Bender [66] suggested children with schizophrenia were more likely to develop CD. Subsequently, four cases of $C D$ among 37 adult males with schizophrenia admitted to the Institute of Pennsylvania Hospital over the course of one year were described [97] and additional case reports followed [98-100].

Studies examining the link between schizophrenia and gluten during World War II found hospital admissions for schizophrenia decreased in areas of lower grain consumption, whereas admissions increased in countries with higher wheat consumption [67,101]. A milk- and cereal-free diet was reported to improve schizophrenic symptoms, and inpatients on this diet were moved to a non-locked ward quicker than those with gluten added to their diet [102]. A follow-up investigation found schizophrenic patients on a GFD were discharged twice as quickly as those not on a GFD [103]. Over a decade later, fewer cases of schizophrenia were identified in countries where grain consumption was low. Furthermore, when grain consumption increased, the prevalence of schizophrenia increased also [104].

In a study of 7,997 people admitted to a Danish psychiatric hospital for the first time with a diagnosis of schizophrenia, CD was found to be a risk factor for schizophrenia. Individuals with $C D$ had a 3.2 fold increased relative risk of developing schizophrenia $(p<0.0001)$ [105].

Reports of increased risk of schizophrenia in individuals with $C D$ have generated controversy, however. A reexamination of the data linking schizophrenia with $C D$ pointed out that if parents of individuals with schizophrenia were excluded from the data, the prevalence of CD was no higher than in a control population [106]. In a study using data from the UK General Practice Research Database, no increased prevalence of schizophrenia was found in individuals with CD compared with the general population [107]. Also, in a study of 100 Iranian inpatients with schizophrenia, no increased rate of $C D$ was found [108].

Explorations of the effects of a GFD on schizophrenic symptoms have demonstrated mixed results. While some studies show no effect [109-111], others demonstrate marked improvement in a subset of individuals with schizophrenia [112-115]. It has been suggested that the presence of antibodies to tTG or gliadin might be a biomarker that could help identify which schizophrenic individuals would respond to a GFD [114].

Several studies examining possible genetic and pathophysiological similarities between $\mathrm{CD}$ and schizophrenia have produced conflicting results. One study found abnormal intestinal permeability in individuals with schizophrenia [116], but this finding was not confirmed in a subsequent study [117]. A positive correlation was reported between plasma amino acid levels in individuals with schizophrenia and individuals with $C D$ [118]. However, a reanalysis of the same data described this association as spurious [119].

Studies exploring a possible genetic linkage between $C D$ and schizophrenia have also produced contradictory results $[120,121]$. A positive correlation between the amount of a leukocyte migration inhibition factor produced by peripheral blood lymphocytes following gluten challenge in individuals with schizophrenia and CD has been described [122].

In an effort to determine whether gluten might produce schizophrenic symptoms, intracerebral injections of gliadin polypeptides fractions were performed on rats. After high dose injections, reactions such as seizures, perseverative behaviors, and other unusual behaviors were noted. The authors suggested gluten might be related to the pathogenesis of schizophrenia [123]. A follow up report suggested schizophrenia was caused by neuroactive peptides produced during digestion of certain food proteins [124]. This hypothesis was supported by the finding that food-derived opioid peptides known as exorphins were present in gluten [125-127]. These peptides were subsequently studied as a possible common etiological factor in CD and schizophrenia [128]. A quarter of a century later, exorphins were reported to produce antioxidant and epigenetic changes [129]. Exorphins were also suggested to be responsible for the absence of classical $\mathrm{Gl}$ symptoms in individuals with asymptomatic CD [130].

In the 1970's, studies were performed to investigate whether antibodies to gluten were more common in schizophrenic patients than in healthy controls. An increased frequency of anti-gliadin antibodies in hospitalized schizophrenic patients was found. However, these same antibodies were increased in hospitalized non-schizophrenic patients as well. The frequency in all psychiatric patients was more than six times higher than in healthy controls and was significantly higher than the frequency found in hospitalized non-psychiatric patients. The authors proposed sustained emotional distress increases the likelihood 
of developing anti-gliadin antibodies by decreasing gut-barrier function, thus permitting the absorption of gliadin polypeptides [131].

In subsequent studies, individuals with schizophrenia were found to have elevated levels of antibodies to gliadin [132,133], tissue transglutaminase 6 (tTG6) [134], and Saccharomyces cerevisiae (a marker of intestinal inflammation) [135] compared with controls.

A meta-analysis examining biomarkers of gluten sensitivity in individuals with schizophrenia found five biomarkers were significantly elevated compared with controls. These were: antigliadin IgG, anti-gliadin IgA, anti-tTG2 IgA, anti-gliadin (unspecified isotype) and anti-wheat [136].

A different study found no correlation between selected antibody levels in individuals with CD and schizophrenia [137], although this study was criticized for its small sample size [138]. Other investigations found no difference in the incidence of reticulin antibodies between individuals with $C D$ and schizophrenia $[139,140]$, however, reticulin antibodies are no longer considered useful in the diagnosis of CD [141]. Schizophrenia patients and otherwise healthy CD patients were tested for antibodies to tTG2 and deamidated gliadin. Levels of these antibodies were not found to be increased in individuals with schizophrenia compared with controls [142].

\section{Autism spectrum disorders}

Autism Spectrum Disorders (ASDs) have been linked with GI symptoms in several studies. Children with ASD experience a higher rate of GI symptoms than controls [143] and $40-60 \%$ of ASD children suffer from GI problems [144]. Children with more severe autism are likely to have more severe GI symptoms, and children with more severe GI symptoms are more likely to have more severe autism [145].

Asperger [146] discussed a possible link between Asperger Syndrome and CD more than a half century ago. Subsequently, Goodwin and Goodwin [147] hypothesized a possible association between autism and gluten in their case report of child with autism who demonstrated improvement following the initiation of a GFD. Return to a normal diet resulted in an exacerbation of autistic symptoms [148]. Subsequently, several additional studies described a link between autism and CD [149-153]. However, other studies found no association between these disorders $[154,155]$.

Several studies describe increased intestinal permeability in ASD [156-158], but not all confirm this finding [158]. Individuals with ASD have also been demonstrated to have increased permeability to food antigens containing gliadin [159] along with altered blood brain barrier (BBB) integrity [160].

Investigators have reported improvement in ASD symptoms following the introduction of a GFD [161-166]. However, others report minimal, if any, correlation between ASD symptoms and changes in dietary gluten [167-171]. One author suggested a subset of individuals with autism might benefit from a GFD [172], but thus far the symptoms or testing profile of these individuals remains unclear.
A possible link between ASD and antibodies commonly found in $C D$ has been reported. Individuals with serological markers for CD but normal mucosa were found to be three times more likely to develop autism in the future [173]. The authors of this study suggested these individuals might suffer from non-celiac gluten sensitivity (NCGS) rather than CD. Levels of anti-gliadin IgG and anti-deamidated gliadin IgG have been reported to be elevated in individuals with ASD compared with controls [159,174]. Antigliadin IgG levels were significantly higher in children with ASD who also reported $\mathrm{Gl}$ symptoms than in those without $\mathrm{Gl}$ symptoms. The levels of antibodies to deamidated gliadin and tTG2 did not differ between individuals with CD and controls [174].

\section{Eating disorders}

Nearly a century after Anorexia Nervosa was first described [175], CD was reported to occur in association with eating disorders (ED) [176]. Numerous case reports describe ED cooccurring with CD [176-182]. In addition, several clinical studies have examined the link between ED and CD. Findings from these studies include an increase in altered or disordered eating behavior in $C D$ patients compared with healthy controls [183-185] and a higher than expected rate of ED in adolescents with CD [186].

In a study examining the personality characteristics of female adolescents with $C D$, individuals with $C D$ and a comorbid ED were found to be older, had a higher current BMI, higher maximum $\mathrm{BMI}$, higher depression scores, and more dietary transgressions than individuals with $C D$ but no ED. The authors concluded that adolescents with $C D$ should be monitored for $\mathrm{BMI}$, dietary transgressions, personality factors, and depressive symptoms [187].

Not all studies support a positive association between $C D$ and ED's, however. The authors of a review of psychiatric disorders in $C D$ surmised it is unclear whether a causal link exists between eating disorders and $C D$ [95]. A prospective study of 154 children and adolescents with ED found none who suffered from CD [188]. A retrospective chart review of 494 patients who had been evaluated for an ED and screened for CD found 10 (2\%) who tested positive for anti-tTG antibodies. Of those individuals, 4 had biopsy confirmed CD via endoscopy for an overall prevalence rate of $0.8 \%$. Given that this prevalence rate is similar to the rate found in the general population, the authors suggested routine screening of individuals with EDs for CD is not indicated [189]. In a similar study, 177 individuals with anorexia nervosa were screened for CD by checking levels of serum IgA and IgG to tTG. The prevalence rate of CD was found to be similar to that observed in the general population [190].

Pica has been reported to occur in association with $C D$, although descriptions are limited to case studies [191-193]. Iron deficiency has been proposed as one cause of pica, and iron deficiency may occur in $C D$ as a result of malabsorption. The complete resolution of pica was reported in 3 children with comorbid CD and pica following the introduction of a GFD [191].

In summary, although the connection between CD and EDs remains controversial, it is clear that an incorrect diagnosis of an 
ED can obscure a correct diagnosis of CD [181,194] and CD can produce disordered eating behavior [195]. Clinicians should remain vigilant to the possibility of underlying $C D$ when a patient presents with symptoms of an ED, and should explore the possibility of disordered eating behavior in patients with $C D$. At this time, there is insufficient evidence to support routine screening of individuals with ED for CD.

\section{Attention-deficit/hyperactivity disorder (ADHD)}

An association between Attention-Deficit/Hyperactivity Disorder (ADHD) and $C D$ has been reported. A retrospective study found ADHD-like symptomatology was "over represented" in 132 individuals with untreated CD compared to the general population [196]. These symptoms improved following 6-months on a GFD. The majority (74\%) of individuals wanted to continue the GFD following the study due to significant relief of their symptoms [196]. This study lacked a control group, however.

A subsequent study measured levels of anti-gliadin antibodies (AGA) and anti-endomysium (ESA) antibodies in 67 individuals with ADHD. Ten of the 67 individuals were found to be positive for these antibodies. Furthermore, subjects and their parents reported significant improvement in behavior and functioning following six months on a GFD [197].

Not all studies support the finding of a positive association between $C D$ and $A D H D$, however. In a Turkish study, serum levels of IgA and IgG to tTG were evaluated in 362 children and adolescents who met DSM-IV-TR criteria for ADHD. Seropositive subjects then underwent endoscopic duodenal biopsy. Seropositive rates were similar in the ADHD and control groups [198].

In a recent review, eight studies reporting an association between $C D$ and ADHD were evaluated. Inconsistent results were found with only three studies reporting a positive correlation between $C D$ and ADHD. The authors found insufficient evidence to support routine screening of ADHD patients for CD (or vice versa) or institution of a GFD in ADHD [199].

\section{Discussion}

Studies examining an association between CD and comorbid psychiatric disorders are fraught with numerous limitations. These include: disparities in study design, small sample size, lack of controls, differing diagnostic criteria, varying levels of psychopathology between the randomized groups, inconsistent status on a GFD, different lengths of treatment, dissimilar outcome measures, disparate ages of subjects, and variable assessment for the presence of serological markers associated with CD [200,201]. Despite these limitations, evidence exists to support an association between $C D$ and psychiatric disorders, even if only in a subset of $C D$ patients.

Numerous pathophysiological mechanisms have been proposed to explain the association between $C D$ and psychiatric disorders. These include: toxic effects of gluten, an autoimmune reaction triggered by gluten, psychological reactions to the physical symptoms of CD resulting in behavioral changes [187], elevated production of nitric oxide, and malabsorption syndromes resulting in deficiencies of tryptophan, thiamine (Vitamin B1), pyridoxine (Vitamin B6), folic acid (Vitamin B9), and cyanocobalamin (Vitamin B12).

Given the high rate of unrecognized $C D$ in the general population [13], a high index of suspicion is required to identify psychiatric patients who may be suffering from undiagnosed CD. Also, in psychiatric patients who are resistant to traditional therapeutic interventions, a diagnosis of $C D$ should be considered if symptoms of $C D$ are present or if a positive family history of $C D$ exists. By understanding the myriad clinical presentations of $C D$, clinicians can better identify patients who are appropriate candidates for serological screening for $C D$, thus improving the chances of a positive clinical outcome.

Based upon World Health Organization criteria, Fasano recommended mass screening for $\mathrm{CD}$. Other authors have recommended genetic screening for at-risk infants. Given the increasing prevalence of $C D$, the difficulty diagnosing this condition based upon varying clinical presentations, and the possible absence of symptoms, we feel it is important for clinicians to be aware of the possibility of $C D$ in patients with psychiatric conditions and consider ordering serological tests (e.g., anti-tTG antibodies) as part of the diagnostic work up in patients who present with psychiatric disorders known to cooccur with $C D$. However, studies examining the prevalence of $C D$ in psychiatric disorders have provided inconsistent results. Therefore, we do not recommend screening all psychiatric patients for $C D$.

Additional studies are needed to further explore the relationship between psychiatric disorders and CD. Elevated antibody levels found to co-occur in $C D$ and certain psychiatric disorders provide a clue that may lead to a better understanding of common pathophysiological mechanisms and result in new treatments for psychiatric conditions. Furthermore, additional investigations into the effects of $C D$ on the blood brain barrier are needed.

\section{References}

1. Sollid LM, McAdam SN, Molberg O, Quarsten H, Arentz-Hansen $\mathrm{H}$, et al. (2001) Genes and environment in celiac disease. Acta Odont Scand 59: 183-186.

2. Campagna G, Pesce M, Tatangelo R, Rizzuto A, La Fratta I, et al. (2016) The progression of coeliac disease: its neurological and psychiatric implications. Nutr Res Rev epub: 1-11.

3. Weiser H (1995) The precipitating factor in coeliac disease. Ballieres Clin Gastroenterolog 9: 199-207.

4. Belton PS (1999) On the elasticity of wheat gluten. Journal of Cereal Science 29: 103-107.

5. Weiser H (2007) Chemistry of gluten proteins. Food Microbiology 24: 115-119.

6. Lamacchia C, Camarca A, Picascia S, Di Luccia A, Gianfrani C (2014) Cereal-based gluten-free food: How to reconcile nutritional and technological properties of wheat proteins with safety for celiac disease patients. Nutrients 6: 575-590.

7. Qiao SW, Sollid LM, Blumberg RS (2009) Antigen presentation in celiac disease. Curr Opin Immunol 21: 111-117. 
8. Balakeriva AV, Zamyatnin AA (2016) Properties of gluten intolerance: Gluten structure, evolution, pathogenicity and detoxification capabilities. Nutrients 8: 1-27.

9. Bai JC, Fried M, Corazza GR, Schuppan D, Farthing M, et al. (2013) World Gastroenterology Organisation global guidelines on celiac disease. J Clin Gastoenterol 47: 121-126.

10. Gee S (1888) On the coeliac disease. St Bart Hosp Rep 24: 17-20.

11. Dicke WK Coeliakie MD (1950) Thesis, Utrecht.

12. Bozzola M, Meazza C, Maggiore G, Nastasio S (2014) Celiac Disease: An update. New York: Nova Science.

13. Fasano A, Catassi C (2001) Current approaches to diagnosis and treatment of celiac disease: An evolving spectrum. Gastroenterology 120: 636-651.

14. Catassi C, Gatti S, Lionetti E (2015) World perspective and celiac disease epidemiology. Dig Dis 33: 144-146.

15. Kratzer W, Kibele M, Akinli A, Porzner M, Boehm BO, et al. (2013) Prevalence of celiac disease in Germany: A prospective follow-up study. World J Gastroenterol 19: 2612-2620.

16. Castassi C, Gatti S, Fasano A (2014) The new epidemiology of celiac disease. J Pediatr Gastroenterol Nutr 59: S7-S8.

17. Rubio-Tapia A, Kyle RA, Kaplan EL, Johnson DR, Page W, et al. (2009) Increased prevalence and mortality in undiagnosed celiac disease. Gastroenterology 137: 88-93.

18. Lohi S, Mustalahti K, Kaukinen K, Laurila K, Collin P, et al. (2007) Increasing prevalence of coeliac disease over time. Aliment Pharmacol \& Ther 26: 1217-1225.

19. Catassi C, Kryszak D, Bhatti B, Sturgeon C, Helzlsouer K, et al. (2010) Natural history of celiac disease autoimmunity in a USA cohort followed since 1974. Ann Med 42: 530-538.

20. Tovoli F, Masi C, Guidetti E, Negrini G, Paterini P, et al. (2015) Clinical and diagnostic aspects of gluten related disorders. World J Clin Cases 16: 275-284.

21. Carlsson A (2016) Currently diagnosed cases of coeliac disease are just the tip of the iceberg. Acta Pediatrica 105: 346-348.

22. Megiorni $F$, Mora B, Bonamico $M$, Barbato $M$, Nenna $R$, et al. (2009) HLA-DQ and risk gradient for celiac disease. Hum Immunol 70: 55-59.

23. Sarno M, Discepolo V, Troncone R, Auricchio R (2015) Risk factors for celiac disease. Ital J Pediat 41: 57.

24. Cecilio LA, Bonatto MW (2015) The prevalence of HLA DQ2 and DQ8 in patients with celiac disease, in family and in general population. ABCD Arq Bra Cir Dig 28: 183-185.

25. Trynka G, Hunt KA, Bockett NA, Romanos J, Mistry V, et al. (2011) Dense genotyping identifies and localizes multiple common and rare variant association signals in celiac disease. Nat Genet 43: 1193-1201.

26. Namatovu F, Lindkvist $M$, Olsson C, Ivarsson A, Sandström O (2016) Season and region of birth as risk factors for coeliac disease a key to the aetiology? Arch Dis Child 101: 1114-1118.

27. Olsson C, Stenlund H, Hörnell A, Hernell O, Ivarsson A (2009) Regional variation in celiac disease risk within Sweden revealed by the nationwide prospective incidence register. Acta Paediatrica 98: 337-342.

28. Capriati T, Francavilla R, Castellaneta S, Ferretti F, Diamanti A (2015) Impact of the birth's season on the development of celiac disease in Italy. Eur J Pediatr 174: 1657-1663.
29. Tanpowpong P, Obuch JC, Jiang H, McCarty CE, Katz AJ, et al. (2013) Multicenter study on season of birth and celiac disease: Evidence for a new theoretical model of pathogenesis. J Pediatr 162: 501-504.

30. Caminero A, Galipeau HJ, McCarville JL, Johnston CS, Bernier SP, et al. (2016) Duodenal bacteria from patients with celiac disease and healthy subjects distinctly affect gluten breakdown and immunogenicity. Gastroenterology 151: 670-683.

31. Cenit MC, Codoñer-Franch P, Sanz Y (2016) Gut microbiota and risk of developing celiac disease. J Clin Gastroenterol 50: S148-S152.

32. Kagnoff MF, Paterson YJ, Kumar PJ, Kasarda DD, Carbone FR, et al. (1987) Evidence for the role of a human intestinal adenovirus in the pathogenesis of coeliac disease. Gut 28: 995-1001.

33. Pagliari D, Urgesi R, Frosali S, Riccioni ME, Newton EE, et al. (2015) The interaction among microbiota, immunity, and genetic and dietary factors is the condicio sine qua non celiac disease can develop. J Immunol Res 2015:123653.

34. Ludvigsson JF, Fasano A (2012)Timing of introduction of gluten and celiac disease risk. Ann Nutr Metab 60: 22-29.

35. Siliano M, Agostoni C, Guandalini S (2010) Effect of the timing of gluten intolerance on the development of celiac disease. World J Gastroenterol 16: 1939-1942.

36. Aronsson CA, Lee HS, Liu E, Uusitalo U, Hummel S, et al. (2015) Age at gluten introduction and risk of celiac disease. Pediatrics 135: 239-245.

37. Chmielewsda A, Pieścik-Lech M, Szajewska H, Shamir R (2015) Primary prevention of celiac disease: Environmental factors with a focus on early nutrition. Ann Nutr Metab 67: 43-50.

38. Lionetti E, Castellaneta S, Francavilla R, Pulvirenti A, Tonutti E, et al. (2014) Introduction of gluten, HLA status, and the risk of celiac disease in children. N Eng J Med 371: 1295-1303.

39. Lammers KM, Lu R, Brownley J, Lu B, Gerard C, et al. (2008) Gliadin induces an increase in intestinal permeability and zonulin release by binding to the chemokine receptor CXCR3. Gastroenterology 135: 194-204.

40. Clemente MG, De Virgiliis S, Kang JS, Macatagney R, Musu MP, et al. (2003) Early effects of gliadin on enterocyte intracellular signaling involved in intestinal barrier function. Gut 52: 218-223.

41. Wang W, Uzzau S, Goldblum SE, Fasano A (2000) Human zonulin, a potential modulator of intestinal tight junctions. J Cell Sci 113 $4435-4440$

42. Fasano A (2011) Zonulin and its regulation of intestinal barrier function: The biological door to inflammation, autoimmunity, and cancer. Physiol Rev 91: 151-175.

43. Krug SM, Schulzke JD, Fromm M (2014) Tight junction, selective permeability, and related diseases. Seminars in Cell \& Developmental Biology 36: 166-176.

44. Hausch F, Shan L, Santiago NA, Gray GM, Khosla C (2002) Intestina digestive resistance of immunodominant gliadin peptides. Am J Gatrotinest Liver Physiol 283: G996-G1003.

45. Kim CY, Quarsten H, Bergseng E, Khosla C, Sollid LM (2004) Structural basis for HLA-DQ2-mediated presentation of gluten epitopes in celiac disease. PNAS 101: 4175-4179.

46. Sanders DS, Hurlstone DP, Stokes RO, Rashid F, Milford-Ward A, et al. (2002) Changing face of adult coeliac disease: experience of a single university hospital in South Yorkshire. Postgrad Med 78 31-33. 
47. Norström F, Lindholm L, Sandström O, Nordyke K, Ivarsson A (2011) Delay to celiac disease diagnosis and its implications for health-related quality of life. BMC Gastroenterology 11: 118.

48. Gibert A, Kruizinga AG, Neuhold S, Houben GF, Canela MA, et al. (2013) Might gluten traces in wheat substitutes pose a risk in patients with celiac disease? A population-based probabilistic approach to risk estimation. Am J Clin Nutr 97: 109-116.

49. Kohout $P$ (2001) Small bowel permeability in diagnosis of celiac disease and monitoring of compliance of a gluten-free diet (gut permeability in celiac disease). Acta Medica 44: 101-104.

50. Tripathi A, Lammers KM, Goldblum S, Shea-Donohue T, NetzelArnett S, et al. (2009) Identification of human zonulin, a physiological modulator or tight junctions, as prehaptoglobin-2. Proc Nat Acad Sci 106: 16799-16804.

51. Leffler DA, Green PH, Fasano A (2015) Extraintestinal manifestations of coeliac disease. Nat Rev Gastroenterol Hepatol 12: $561-571$

52. Gillett HR, Arnott IDR, McIntyre M, Campbell S, Dahele A, et al. (2002) Successful infliximab treatment for steroid-refractory celiac disease: A case report. Gastroenterol 22: 800-805.

53. Castantino G, della Torre A, lo Presti MA, Caruso R, Mazzon E (2008) Fries W. Treatment of life-threatening type I refractory coeliac disease with long-term infliximab. Dig Liver Dis 40: 74-77.

54. Rawal N, Twaddell W, Fasano A, Blanchard S, Safta A (2015) Remission of refractory celiac disease with infliximab in a pediatric patient. ACG Case Rep J 2: 121-123.

55. Khaleghi S, Ju JM, Lamba A, Murray JA (2016) The potential utility of tight junction regulation in celiac disease: focus on larazotide acetate. Ther Adv Gastroenterol 9: 37-49.

56. Kelly CP, Green PHR, Murray JA, DiMarino A, Colatrella A, et al. (2013) Larazotide acetate in patients with coeliac disease undergoing a gluten challenge: a randomized placebo-controlled study. Aliment Pharmacol Ther 37: 252-262.

57. Leffler DA, Kelly CP, Abdallah $\mathrm{HZ}$, Colatrella AM, Harris LA, et al. (2012) A randomized, double-blind study of larazotide acetate to prevent the activation of celiac disease during gluten challenge. Am J Gastroenterol 107: 1554-1562.

58. Leffler DA, Kelly CP, Green PHR, Fedorak RN, DiMarino A, et al. (2015) Larazotide acetate for persistent symptoms of celiac disease despite a gluten-free diet: a randomized controlled trial. Gastroenterol 148: 1311-1319.

59. Paterson BM, Lammers KM, Arrieta MC, Fasano A, Meddings JB (2007) The safety, tolerance, pharmacokinetic and pharmacodynamics effects of single doses of AT-1001 in coeliac disease subjects: a proof of concept study. Aliment Pharmacol Ther 26: 757-766.

60. Van Beurden YH, van Gils T, van Gils N, Kassam Z, Mulder CJJ, et al. (2016) Serendipity in refractory celiac disease: full recovery of duodenal villi and clinical symptoms after fecal microbiota transfer. J Gastrointestin Liver Dis 25: 385-388.

61. Hernandez L, Green PH (2006) Extraintestinal manifestations of celiac disease. Curr Gastroenterol Rep. 8: 383-389.

62. Visser J, Rozing J, Aspone A, Lammers K, Fasano A (2009) Tight junctions, intestinal permeability, and autoimmunity celiac disease and type 1 diabetes paradigms. Ann N Y Acad Sci 1165: 195-205.

63. Serena G, Camhi S, Sturgeon C, Yan S, Fasano A (2015) The role of gluten in celiac disease and type 1 diabetes. Nutrients 7: 7143-7162.
64. Fasano A (2011) Leaky gut and autoimmune diseases. Clinic Rev Allerg Immunol 42: 71-78.

65. Zingone F, Swift GL, Card TR, Sanders DS, Ludvigsson JF, et al. (2014) Psychological morbidity of celiac disease: a review of the literature. United European Gastroenterol J 3: 136-145.

66. Bender L (1953) Childhood schizophrenia. Psychiatr Q 27: 663-681.

67. Dohan FC (1966) Wheat "consumption" and hospital admissions for schizophrenia during World War II. A preliminary report. Am J Clin Nutr 18: 7-10.

68. Prugh DG (1951) A preliminary report on the role of emotional factors in idiopathic celiac disease. Psychosom Med 13: 220-241.

69. Addolorato G, Stefanini GF, Capristo E, Caputo F, Gasbarrini A, et al. (1996) Anxiety and depression in adult untreated celiac subjects and in patients affected by inflammatory bowel disease: a personality "trait" or a reactive illness? Hepatogastroenterology 43: 1513-1517.

70. Fera T, Cascio B, Angelini G, Martini S, Guidetti CS (2003) Affective disorders and quality of life in adult coeliac disease patients on a gluten-free diet. Eur J Gastroenterol Hepatol 15: 1287-1292.

71. Carta MG, Hardoy MC, Boi MF, Mariotti S, Carpiniello B, et al. (2002) Association between panic disorder, major depressive disorder and celiac disease: A possible role of thyroid autoimmunity. J Psychosom Res 53: 789-793.

72. Cicarelli G, Della Roca G, Amboni M, Ciacci C, Mazzacca G, et al. (2003) Clinical and neurological abnormalities in adult celiac disease. Neurol Sci 24: 311-317.

73. Pynnönen PA, Isometsä ET, Aronen ET, Verkasalo MA, Savilahti E, et al. (2004) Mental disorders in adolescents with celiac disease. Psychosomatics 45: 325-335.

74. Siniscalchi $M$, lovino $P$, Tortora R, Forestiero $S$, Somma $A$, et al. (2005) Fatigue in adult coeliac disease. Aliment Pharmacol Ther 22: 489-494.

75. Ludvigsson JF, Reutfors J, Ösby U, Ekbom A, Montgomery SM (2007) Coeliac disease and risk of mood disorders - a general population-based cohort study. J Affect Disord 99: 117-126.

76. Mazzone L, Reale L, Spina M, Gaurnera M, Lionetti E, et al. (2011) Compliant gluten-free children with celiac disease: an evaluation of psychological distress. BMC Pediatr 11: 46.

77. Van Hees NJM, Van der Does W, Giltay EJ (2013) Coeliac disease, diet adherence and depressive symptoms. J Psychosom Res 74: 155-160.

78. Smith DF, Gerdes LU (2012) Meta-analysis on anxiety and depression in adult celiac disease. Acta Psychiatr Scand 125: 189-193.

79. Ludvigsson JF, Seelgren C, Runeson B, Långström N, Lichtenstein P (2011) Increased suicide risk in coeliac disease - a Swedish nationwide cohort study. Dig Liver Dis 43: 616-622.

80. Garud S, Leffler D, Dennis M, Edwards-George J, Saryan D, et al. (2009) Interaction between psychiatric and autoimmune disorders in coeliac disease patients in the Northeaster United States. Aliment Pharmacol Ther 29: 898-905.

81. Accomando S, Fragapane ML, Montaperto D, Trizzino A, Amato GM, et al. (2005) Coeliac disease and depression: two related entities? Dig Liver Dis 37: 298-299.

82. Häuser W, Janke KH, Klump B, Gregor M, Hinz A (2010) Anxiety and depression in adult patients with celiac disease on a glutenfree diet. World J Gastroenterol 16: 2780-2787. 
83. Roos S, Kärner A, Hallert C (2006) Psychological well-being of adult coeliac patients treated for 10 years. Dig Liver Dis 38: 177-182.

84. Esenyel S, Ünal F, Vural P (2014). Depression and anxiety in child and adolescents with follow-up celiac disease and in their families. Turk J Gastroenterol 25: 381-385.

85. Eaton WW, Pedersen MG, Nielsen PR, Mortensen PB (2010) Autoimmune diseases, bipolar disorder, and non-affective psychosis. Bipolar Disord 12: 638-646.

86. Carta MG, Conti A, Lecca F, Sancassiani F, Cossu G, etal. (2015) The burden of depressive and bipolar disorders in celiac disease. Clin Pract Epidemiol Ment Health 11: 180-185.

87. Saleem A, O Connor HJ, O Regan P (2012) Adult coeliac disease in Ireland: a case study. Ir J Med Sci 181: 225-229.

88. Kessler RC, Chiu WT, Demler O, Walters E (2005). Prevalence, severity, and comorbidity of twelve-month DSM-IV disorders in the National Comorbidity Survey Replication (NCS-R). Arch Gen Psych 62: 617-627.

89. Ruggieri M, Incorprora G, Polizzi A, Parano E, Spina M, et al. (2008) Low prevalence of neurologic and psychiatric manifestations in children with gluten sensitivity. J Pediatr 152: 244-249.

90. Dickerson F, Stallings C, Origoni A, Vaughan C, Khushalani S, et al. (2011) Markers of gluten sensitivity and celiac disease in bipolar disorder. Bipolar Disord 13: 52-58.

91. Dickerson F, Stallings C, Origoni A, Vaughan C, Khushalani S, et al. (2012) Markers of gluten sensitivity in acute mania: a longitudinal study. Psychiatry Res 196: 68-71.

92. Sidhom O, Laadhar L, Zitouni M, Alaya NB, Rafrafi R, et al. (2012) Spectrum of autoantibodies in Tunisian psychiatric inpatients. Immunol Invest 41: 538-549.

93. Addolorato G, Capristo E, Ghittoni G, Valeri C, Mascianà VR, et al (2001) Anxiety but not depression decreases in coeliac patients after one-year gluten-free diet: a longitudinal study. Scand J Gastroenterol 36: 502-506.

94. Addolorato G, Mirijello A, D’Angelo C, Leggio L, Ferrulli A, et al. (2008) Social phobia in coeliac disease. Scand J Gastroenterol 43 410-415.

95. Kalaydijian AE, Eaton W, Cascella N, Fasano A (2006) The gluten connection: the association between schizophrenia and celiac disease. Acta Psychiatr Scand 113: 82-90.

96. Delichatsios HK, Leonard MM, Fasano A, Nosé V (2016) Case 14-2016: a 37-year-old woman with adult-onset psychosis. N Engl J Med 374: 1875-1883.

97. Graff H, Hanford A (1961) Celiac syndrome in the case histories of five schizophrenics. Psychiatr Q 35: 306-318.

98. Donoho J (1973) Schizophrenia, cereal grains and celiac disease. Del Med J 45: 303-304

99. De Santis A, Addolorato G, Romito A, Caputo S, Giordano A, et al. (1997) Schizophrenic symptoms and SPECT abnormalities in a coeliac patient: regression after a gluten-free diet. J Intern Med 242: 421-423.

100. Desplat-Jégo S, Bernard $D$, Bagnères $D$, Frances $Y$ (2003) Neuropsychiatric symptoms in the elderly: let us not forget celiac

101. Dohan FC (1976) The possible pathogenic effect of cereal grains in schizophrenia. Acta Neurol (Napoli) 31: 195-205.

102. Dohan FC, Grasberger JC, Lowell FM, Johnston HT, Arbegast AW (1969) Relapsed schizophrenics: more rapid improvement on a milk- and cereal-free diet. Brit J Psychiatr 115: 595-596.
103. Dohan FC, Grasberger JC (1973) Relapsed schizophrenics: earlier discharge from the hospital after cereal-free, milk-free diet. Am J Psychiatry 130: 685-688.

104. Dohan FC, Harper EH, Clark MH, Rodrigue RB, Zigas V (1984) Is schizophrenia rare if grain is rare? Biol Psychiatry 19: 385-399.

105. Eaton WE, Mortensen PB, Agerbo E, Byrne M, Mors O, et al. (2004) Coeliac disease and schizophrenia: population based case control study with linkage of Danish national registers. BMJ 328: 438-439.

106. Campbell EB, Foley S (2004) Coeliac disease and schizophrenia: data do not support hypothesis. BMJ 328: 1017.

107. West J, Logan RF, Hubbard RB, Card TR (2006) Risk of schizophrenia in people with coeliac disease, ulcerative colitis and Crohn's disease: a general population-based study. Aliment Pharmacol Ther 23: 71-74.

108. Khoshbaten M, Nejad MR, Sharifi N, Fakhari A, Golammnejad M, et al. (2012) Celiac disease in patients with chronic psychiatric disorders. Gastroenterol Hepatol Bed Bench. 5: 90-93.

109. Potkin SG, Weinberger D, Kleinman J, Nasrallah H, Luchins D, et al. (1981) Wheat gluten challenge in schizophrenic patients. Am J Psychiatry 138: 1208-1211.

110. Storms LH, Clopton JM, Wright C (1982) Effects of gluten on schizophrenics. Arch Gen Psychiatry 39: 323-327.

111. Osborne M, Crayton JW, Javaid J, Davis JM (1982) Lack of effect of a gluten-free diet on neuroleptic blood levels in schizophrenic patients. Biol Psychiatry 17: 627-629.

112. Rice JR, Ham CH, Gore WE (1978) Another look at gluten in schizophrenia. Am J Psychiatry 135: 1417-1418.

113. Singh MM, Kay SR (1976) Wheat gluten as a pathogenic factor in schizophrenia. Science 191: 401-402.

114. Jackson J, Eaton W, Fasano A, Warfel D, Feldman S, et al. (2012) A gluten-free diet in people with schizophrenia and anti-tissue transglutaminase or anti-gliadin antibodies. Schizophr Res 140: 262-263.

115. Vlissides DN, Venulet A, Jenner FA (1986) A double-blind glutenfree/gluten-load controlled trial in a secure ward population. $\mathrm{Br} J$ Psychiatry 148: 447-452.

116. Wood NC, Hamilton I, Axon AT, Khan SA, Quirke P, et al. (1987) Abnormal intestinal permeability: an aetiological factor in chronic psychiatric disorders? Br J Psychiatry. 150: 853-856.

117. Lambert MT, Bjarnason I, Connelly J, Crow TJ, Johnstone EC, et al. (1989) Small intestine permeability in schizophrenia. $\mathrm{Br} J$ Psychiatry. 155: 619-622.

118. Manowitz P (1978) Amino acid levels in schizophrenia: a clue to etiology. Biol Psychiatry 13: 489-491.

119. Simpson JC (1982) Amino acid levels in schizophrenia and celiac disease: another look. Biol Psychiatry 17: 1353-1357.

120. Jungerius BJ, Bakker SC, Monsuur AJ, Sinke RJ, Kahn RS, et al. (2008) Is MY09B the missing link between schizophrenia and celiac disease? Am J Med Genet Part B 147: 351-355.

121. Law MH, Bradford M, McNamara N, Gajda A, Wei J (2011) No association observed between schizophrenia and non-HLA coeliac disease genes: integration with the initial MYO9B association with coeliac disease. Am J Med Genet Part B 156: 709-719.

122. Ashkenazi A, Krasilowsky D, Levin S, Idar D, Kalian M, et al. (1979) Immunologic reaction of psychotic patients to fractions of gluten. Am J Psychiatry 136: 1306-1309. 
123. Dohan FC, Levitt DR, Kushnir LD (1978) Abnormal behavior after intracerebral injection of polypeptides from wheat gliadin: possible relevance to schizophrenia. Pavlov J Biol Sci 13: 73-82.

124. Dohan F (1980) Hypothesis: genes and neuroactive peptides from food as cause of schizophrenia. Adv Biochem Psychopharmacol 22: $535-548$.

125. Klee WA, Zioudrou C, Streaty RA (1979) Endorphins: peptides with opioid activity isolated from wheat gluten, and their possible role in the etiology of schizophrenia. In: Usdin E, Bunney W, Kline N, Chellenberg $\mathrm{S}$ (eds). Endorphins in Mental Health Research. New York: Oxford University Press.

126. Zioudrou C, Streaty RA, Klee WA (1979) Opioid peptides derived from food proteins. The exorphins. J Biol Chem 254: 2446-2449.

127. Huebner FR, Lieberman KW, Rubino RP, Wall JS (1984) Demonstration of high opioid-like activity in isolated peptides from wheat gluten hydrolysates. Peptides 5: 1139-1147.

128. Paroli E (1988) Opioid peptides from food (the exorphins). World Rev Nutr Diet 55: 58-97.

129. Trivedi MS, Shah JS, Al-Mughairy S, Hodgson NW, Simms B, et al. (2014) Food-derived opioid peptides inhibit cysteine uptake with redox and epigenetic consequences. J Nutr Biochem 25: 1011-1018.

130. Pruimbood L, de Punder K (2015) The opioid effects of gluten exorphins: asymptomatic celiac disease. J Health Popul Nutr 33: 24.

131. Dohan FC, Martin L, Grasberger JC, Boehme D, Cottrell JC (1972) Antibodies to wheat gliadin in blood of psychiatric patients: possible role of emotional factors. Biol Psychiatry 5: 127-137.

132. Reichelt KL, Landmark (1995). Specific IgA antibody increases in schizophrenia. Biol Psychiatry 15: 410-413.

133. Cascella NG, Kryszak D, Bhatti B, Gregory P, Kelly DL, et al. (2011) Prevalence of celiac disease and gluten sensitivity in the United States clinical antipsychotic trials of intervention effectiveness study population. Schizophr Bull 37: 94-100.

134. Cascella NG, Santora D, Gregory P, Kelly DL, Fasano A, et al. (2013) Increased prevalence of transglutaminase 6 antibodies in sera from schizophrenia patients. Schizophr Bull 39: 867-871.

135. Severance EG, Alaedini A, Yang S, Halling M, Gressitt KL, et al. (2012) Gastrointestinal inflammation and associated immune activation in schizophrenia. Schizophr Bull 138: 48-53.

136. Lachance LR, McKenzie K (2014) Biomarkers of gluten sensitivity in patients with non-affective psychosis: a meta-analysis. Schizophr Bull 152: 521-527.

137. Stevens FM, Lloyd R, Geraghty S, Reynolds M, Sarsfield J, et al. (1975) Schizophrenia and coeliac disease: is there a positive relationship? Ir J Med Sci 144: 175.

138. Stevens FM, Lloyd RS, Geraghty SM, Reynolds MT, Sarsfield MJ, et al. (1977) Schizophrenia and coeliac disease-the nature of the relationship. Psychol Med 7: 259-263.

139. Mayo Clinic 2016 Retrieved from: http:// www.mayomedicallaboratories.com/test-catalog/Overview/9275.

140. Samaroo D, Dickerson F, Kasarda DD, Green PHR, Briana C, et al. (2010) Novel immune response to gluten in individuals with schizophrenia. Schizophr Res 118: 248-255.

141. McElhanon BO, McCracken C, Karpen S, Sharp WG (2014) Gastrointestinal symptoms in autism spectrum disorder: a metaanalysis. Pediatrics 133: 872-873.
142. Kraneveld AD, Szklany K, de Theije CGM, Garrsen (2016) Gut-tobrain axis in autism spectrum disorders: central role for the microbiome. Int Rev Neurobiol 131: 263-287.

143. Adams JB, Johansen LJ, Powell LD, Quig D, Rubin RA (2011) Gastrointestinal flora and gastrointestinal status in children with autism-comparisons to typical children and correlation with autism severity. BMC Gastroenterol 11: 22.

144. Asperger H (1961) Psychopathology of children with coeliac disease. Ann Paediatr 197: 346-351.

145. Goodwin MS, Goodwin TC (1969) In a dark mirror. Mental Hygiene 53: $550-563$

146. Goodwin MS, Cowen MA, Goodwin TC (1971) Malabsorption and cerebral dysfunction: a multivariate and comparative study of autistic children. J Autism Child Schizophr 1: 48-62.

147. Sullivan RC (1975) Hunches on some biological factors in autism. J Autism Child Schizophr 5: 177-186.

148. Genius SJ, Bouchard TP (2010) Celiac disease presenting as autism. J Child Neurol 25: 114-119.

149. Atladóttir HO, Pedersen MG, Thorsen P, Mortensen PM, Deleuran $B$, et al. (2009) Association of family history of autoimmune diseases and autism spectrum disorders. Pediatrics 124: 687-694.

150. Calderoni S, Santocchi E, Del Bianco T, Brunori E, Caponi L, et al. (2016) Serological screening for celiac disease in 382 pre-schoolers with autism spectrum disorder. It J Pediatr 42: 98.

151. Pavone L, Fiumara A, Bottaro G, Mazzone D, Coleman M (1997) Autism and celiac disease: failure to validate the hypothesis that a link might exist. Biol Psychiatry 42: 72-75.

152. Batista IC, Gandolfi L, Nobrega YK, Almeida RC, Almeida LM, et al. (2012) Autism spectrum disorder and celiac disease: no evidence for a link. Arq Neuropsiquiatr 70: 28-33.

153. D'Eufemia P, Celli M, Finocchiaro R, Pacifico L, Viozzi L, et al. (1996) Abnormal intestinal permeability in children with autism. Acta Paediatr 85: 1076-1079.

154. de Magistris L, Familiari V, Pascotto A, Sapone A, Frolli A, et al. (2010) Alterations of the intestinal barrier in patients with autism spectrum disorders and in their first-degree relatives. J Pediatr Gastroenterol Nutr 51: 418-424.

155. Dalton N, Chandler S, Turner C, Charman T, Pickles A, et al. (2014) Gut permeability in autism spectrum disorders. Autism Res 7 305-313.

156. De Magistris L, Picardi A, Siniscalco D, Riccio MP, Sapone A, et al. (2013) Antibodies against food antigens in patients with autism spectrum disorders. Biomed Res Int 2013: 729349.

157. Knivsberg AM, Reichelt KL, Høien T, Nødland M (2002) A randomised, controlled study of dietary intervention in autistic syndromes. Nutr Neurosci 5: 251-261.

158. Fiorentino M, Sapone A, Senger S, Camhi SS, Kadzielski AM, et al. (2016) Blood-brain barrier and intestinal epithelial barrier alterations in autism spectrum disorders. Mol Autism 7: 49.

159. Hsu CL, Lin CY, Chen CL, Wang CM, Wong MK (2009) The effects of a gluten and casein-free diet in children with autism: a case report. Chang Gung Med J 32: 459-465.

160. Whiteley P, Rodgers J, Savery D, Shattock P (1999) A gluten-free diet as an intervention for autism and associated spectrum disorders: preliminary findings. Autism 3: 45-65.

161. Whiteley P, Haracopos D, Knivsberg AM, Reichelt KL, Parlar S, et al. (2010) The ScanBrit randomised, controlled, single-blind study of a 
gluten- and casein-free dietary intervention for children with autism spectrum disorders. Nutr Neurosci 13: 87-100.

162. Ghalichi F, Ghaemmaghami J, Malek A, Ostradrahimi A (2016) Effect of gluten free diet on gastrointestinal and behavioral indices for children with autism spectrum disorders: a randomized clinical trial. World J Pediatr 12: 436-442.

163. Hyman SL, Stewart PA, Foley J, Cain U, Peck R, et al. (2016) The gluten-free/casein-free diet: a double-blind challenge trial in children with autism. J Autism Dev Disord 46: 205-220.

164. Lange KW, Hauser J, Reissmann A (2015) Gluten-free and caseinfree diets in the therapy of autism. Curr Opin Clin Nutr Metab Care 18: $572-575$

165. Marí-Bauset S, Zazpe I, Mari-Sanchis A, Llopis-González A, Morales-Suárez-Varela M (2014) Evidence of the gluten-free and casein-free diet in autism spectrum. J Child Neurol 29: 1718-1727.

166. Millward C, Ferriter M, Calver SJ, Connell-Jones GG (2008) Glutenand casein-free diets for autistic spectrum disorder. Cochrane Database Syst Rev.

167. Pusponegoro HD, Ismael S, Firmansyah A, Sastroasmoro S, Vandenplas Y (2015) Gluten and casein supplementation does not increase symptoms in children with autism spectrum disorder. Acta Paediatrica 104: e500-e505.

168. Buie T (2013) The relationship of autism and gluten. Clin Ther 35 578-583.

169. Ludvigsson JF, Reichenberg A, Hultman C, Murray JA (2013) A nationwide study of small intestinal histopathology and risk of autistic spectrum disorders. JAMA Psychiatry 70: 1224-1230.

170. Lau NM, Green PHR, Taylor AK, Hellberg D, Ajamian M, et al. (2013) Markers of celiac disease and gluten sensitivity in children with autism. PLoS One 8: 155.

171. Gull WW (1874) Anorexia Nervosa. Transactions of the Clinical Society of London 7: 22-28.

172. Ferrara A, Fontana VJ (1966) Celiac disease and anorexia nervosa. NY State J Med 15: 1000-1005.

173. Ricca V, Mannucci E, Calabrò A, Di Bernardo M, Cabras PL, et al. (2000)Anorexia nervosa and celiac disease: two case reports. Int J Eat Disord 27: 199-222.

174. Wright K, Smith MS, Mitchell J (1990) Organic diseases mimicking atypical eating disorders. Clin Pediatr (Phila) 29: 325-328.

175. Jost PJ, Stengel SM, Huber W, Sarbia M, Peschel C, et al. (2005) Very severe iron-deficiency anemia in a patient with celiac disease and bulimia nervosa: a case report. Int J Hematol 82: 10-311.

176. Milisavljević N, Cvetković M, Nikolić G, Filipović B (2013) Celiac disease diagnosed after uncomplicated pregnancy in a patient with history of bulimia nervosa. Vojnosanit Pregl 70: 77-79.

177. Yucel B, Ozbey N, Demir K, Polat A, Yager J (2006) Eating disorders and celiac disease: a case report. Int J Eat Disord 39: 530-532.

178. Leffler DA, Dennis M, Edwards George JB, Kelly CP (2007)The interaction between eating disorders and celiac disease: an exploration of 10 cases. Eur J Gastroenterol Hepatol 19: 251-255.

179. Passananti V, Siniscalchi M, Zingone F, Bucci C, Tortora R, et al. (2013) Prevalence of eating disorders in adults with celiac disease. Gastroenterol Res Pract 2013: 491657.

180. Satherly R, Howard R, Higgs S (2015) Disordered eating practices in gastrointestinal disorders. Appetite 84: 240-250.
181. Arigo D, Anskis AM, Smyth JM (2012) Psychiatric comorbidities in women with celiac disease. Chronic IIIn 8: 45-55.

182. Karwautz A, Wagner G, Berger G, Sinnreich U, Grylli V, et al. (2008) Eating pathology in adolescents with celiac disease. Psychosomatics 49: 399-406.

183. Wagner G, Zeiler M, Berger G, Huber WD, Favaro A, et al. (2015) Eating disorders in adolescents with celiac disease: influence of personality characteristics and coping. Eur Eat Disorders Rev 23: 361-370.

184. Kaltsa M, Garoufi A, Tsitsika A, Tsirogianni A, Papasteriades C, et al. (2015) Patients with eating disorders showed no signs of coeliac disease before and after nutritional intervention. Acta Paediatrica 104: e319-323.

185. Saldanha NE, Weiselberg EC, Fisher M (2016) Screening for celiac disease in patients with eating disorders. Int J Adolesc Med Health.

186. Basso MS, Zanna V, Panetta F, Caramadre AM, Ferretti F, et al. (2013) Is the screening for celiac disease useful in anorexia nervosa? Eur J Pediatr 172: 261-263.

187. Korman SH (1990) Pica as a presenting symptom in childhood celiac disease. Am J Clin Nutr 51: 139-141.

188. Santos JA, Werlin SL (1996) Celiac disease in childhood presenting with pica: case report. Wis Med J 95: 581-582.

189. Nield LS, Gillespie S, Riedel BD (2011) A 16-year-old boy with anemia, pica. Pediatr Ann 40: 391-392.

190. Eberman LE, Cleary MA (2005) Celiac disease in an elite female collegiate volleyball athlete: a case report. J Athl Train 40: 360-364.

191. Mascitelli L, Pezzetta F, Goldstein MR (2009) Coeliac disease and anorexia nervosa. Intern Med J 39: 784.

192. Niederhofer H, Pittschieler K (2006) A preliminary investigation of ADHD symptoms in persons with celiac disease. J Atten Disord 10 200-204.

193. Niederhofer H (2011) Association of Attention-Deficit/ Hyperactivity Disorder and celiac disease: a brief report. Prim Care Companion CNS Disord.

194. Güngör S, Celiloğlu OS, Özcan ÖÖ, Raif SG, Selimoğlu MA (2013) Frequency of celiac disease in attention-deficit/hyperactivity disorder. J Pediatr Gastroenterol Nutr 56: 211-214.

195. Ertürk E, Wouters S, Imeraj L, Lampo A (2016) Association of ADHD and celiac disease: what is the evidence? A systematic review of the literature. J Atten Disord.

196. Addolorato G, Leggio L, D’Angelo C, Mirijello A, Ferrulli A, et al. (2008) Affective and psychiatric disorders in celiac disease. Dig Dis 26: $140-148$.

197. Dohan FC (1979) Celiac-type diets in schizophrenia. Am Psychiatry 136: 732-733.

198. Fluegge K (2016) Gluten intolerance and neurodevelopmental disorders: Is nitric oxide the common biomarker linking these conditions? Ann Nutr Metab 69: 54-55.

199. Diaconu G, Burlea M, Grigore I, Anton DT, Trandafir LM (2013) Celiac disease with neurologic manifestations in children. Rev Med Chir Soc Med Nat lasi 117: 88-94.

200. Fasano A (2003) European and North American populations should be screened for coeliac disease. Gut 52: 168-169. 
201. Leonard MM, Serena G, Sturgeon C, Fasano A (2015) Genetics and celiac disease: the importance of screening. Expert Rev Gastroenterol Hepatol 9: 209-215. 